\title{
Pemodelan Tempat Pemberian ASI Ekslusif Di Lingkungan Pekerjaan
}

\author{
Jaji, Antarini idriasari, M Zainal Fikri \\ Fakultas Kedokteran Program Studi Ilmu Keperawatan \\ Corresponding Email: jaji.unsri@gmail.com
}

\begin{abstract}
ABSTRAK
Rendahnya cakupan pemberian ASI merupakan ancaman bagi tumbuh kembang anak. Beberapa hal yang menghambat pemberian ASI eksklusif diantaranya adalah rendahnya pengetahuan ibu dan keluarga mengenai manfaat ASI, serta cara menyusui yang benar. Selain itu kurangnya pelayanan konseling laktasi dan dukungan dari petugas kesehatan, faktor sosial budaya, gencarnya pemasaran susu formula, dan faktor ibu yang bekerja. Beberapa hal yang dapat menfasilitasi pemberian ASI pada ibu bekerja yaitu dukungan lingkungan kantor, dukungan dari atasan, teman kerja, jadwal kerja yang fleksibel, waktu istirahat, sikap rekan kerja yang positif terhadap pemberian ASI, sikap ibu bekerja. Sedangkan beberapa hal yang dapat menghambat pemberian ASI adalah stress psikologis yang disebabkan oleh waktu bekerja yang ketat dan ketidak nyamanan pada saat pemberian ASI. Kurangnya waktu dan lokasi ruangan menyusui juga diakui sebagai salah satu hambatan dalam pemberain ASI selama jam kerja. Kegiatan penyuluhan dan pendampingan pemberian ASI ekslusif merupakan bentuk nyata trias prevensi yang harus dilakukan oleh tenaga kesehatan terutama perawat di PUSKESMAS. Memerah ASI merupakan salah satu solusi untuk tetap memberikan ASI di tempat kerja. 5 fasilitas yang dapat disediakan oleh tampat kerja untuk tetap memberikan ASI yaitu: pompa ASI, ruangan untuk memerah ASI atau ruangan untuk menyusui, waktu istirahat untuk memerah ASI atau untuk menyusui, adanya lemari pendingin untuk tempat menyimpan ASI dan adanya dukungan dari tempat bekerja. Para ibu agar berkomitmen memberikan ASI ekslusif kepada anaknya, dan bagi institusi tempat kerja agar memberikan kesempatan kepada ibu yang mempunyai anak usia 0-6 bulan, tetap memberikan ASInya dengan melonggarkan waktu untuk manajemen ASI perah.
\end{abstract}

Kata kunci: Pemodelan, Tempat Pemberian ASI Ekslusif, Lingkungan Pekerjaan.

\section{ABSTRACT}

The low coverage of breastfeeding is a threat to the growth and development of children. Some of the things that hinder exclusive breastfeeding include the low level of knowledge of mothers and families about the benefits of breastfeeding, and how to breastfeed properly. In addition, the lack of lactation counseling services and support from health workers, socio-cultural factors, the incessant marketing of formula milk, and factors of working mothers. Some things that can facilitate breastfeeding for working mothers are support from the office environment, support from superiors, coworkers, flexible work schedules, rest periods, positive work colleagues 'attitudes towards breastfeeding, working mothers' attitudes. While some things that can hinder breastfeeding are psychological stress caused by tight work time and discomfort at the time of breastfeeding. Lack of time and location of breastfeeding rooms is also recognized as one of the obstacles in breastfeeding during working hours. The counseling and assistance activities of exclusive breastfeeding are a real form of triad prevention that must be carried out by health workers, especially nurses at the community Health centers. Expressing milk is one of the solutions to keep breastfeeding at work. 5 facilities that can be provided by the workplace to keep breastfeeding, namely: a breast milk pump, a room for milking or a room for breastfeeding, rest periods for 
milking or for breastfeeding, there is a refrigerator for storing milk and there is support from the workplace. Mothers are committed to giving exclusive breastfeeding to their children, and for workplace institutions to provide opportunities for mothers who have children aged 0-6 months, continue to give their milk by relaxing time for the management of dairy milk.

Keywords: Modeling, exclusive breastfeeding place, work environment.

\section{PENDAHULUAN}

Pemeberian asi eksklusif ini sering terhalang dengan status pekerjaan ibu. Hal ini membuat ibu bekerja memiliki kesulitan untuk tetap memberikan ASI selama ibu bekerja (Ryan dkk, 2006). Data statistik Indonesia menunjukkan terjadi peningkatan jumlah angka tenaga kerja ibu dalam 2 tahun terakhir. Jumlah ibu yang aktif bekerja meningkat dari sekitar 38 juta pada tahun 2006 menjadi sekitar 41 juta pada tahun 2007. Pada tahun 2007, jumlah tenaga kerja ibu adalah sebanyak $40 \%$, dengan jumah peningkatan utama pada ibu usia produktif. Beberapa penelitian menunjukkan bahwa ibu bekerja mendapatkan kesulitan untuk tetap memberikan ASI pada saat bekerja (Biagioli, 2003).

Rendahnya cakupan pemberian ASI merupakan ancaman bagi tumbuh kembang anak. WHO (2002) melaporkan bahwa pemberian ASI tanpa makanan pendamping ASI pada bayi usia 4-6 bulan masih sangat rendah di beberapa negara Asia. Di Banglades hanya 10\%, Maldives 10\%, Myanmar 14-63\%, India 1-35\%, Sri Lanka 17-57\% dan Thailand 4\%. Di Swedia persentase pemberian ASI saja sebagai makanan utama bayi sebesar $51 \%$ pada bayi 2 bulan, $30 \%$ pada bayi 4 bulan dan $1.8 \%$ pada bayi 6 bulan. Di Amerika Serikat (AS) proporsi menyusui eksklusif adalah $47 \%$ pada bayi 7 hari, 32\% pada bayi 2 bulan, 19\% pada bayi 4 bulan dan $10 \%$ pada bayi usia 6 bulan (Li, 2002). Di Kanada 22\% ibu yang berusia 15 - 49 tahun menyusui anaknya kurang dari 3 bulan dan 35\% menyusui anaknya sampai dengan usia 3 bulan (Palda, 2004).

Beberapa hal yang menghambat pemberian ASI eksklusif diantaranya adalah rendahnya pengetahuan ibu dan keluarga lainnya mengenai manfaat ASI dan cara menyusui yang benar, kurangnya pelayanan konseling laktasi dan dukungan dari petugas kesehatan, faktor sosial budaya, gencarnya pemasaran susu formula, dan faktor ibu yang bekerja (Dinkes,2008). Keadaan yang sama juga terjadi pada ibu yang bekerja. Durasi pemberianASI pada ibu bekerja lebih singkat dari pada durasi pemberian ASI pada ibu tidak bekerja dan berhubungan dengan lama cuti setelah melahirkan (Earlan, Ibrahim dan Harpin, 1997; Ong, 2005; Roe dkk,1999). Selain itu jenis pekerjaan dan lama jam kerja juga menentukan lama pemberian ASI pada ibu bekerja (Kimbro, 2006, Hills-Bonczyk dkk, 1993, Ryan, Zhou dan Arensberg, 2006, Roe dkk, 1999).

Menggabungkan menyusi dengan bekerja melibatkan 2 pihak yaitu pekerja dan tempat bekerja. Adanya dukungan positif dari tempat bekerja dapat mempengaruhi praktek pemberian ASI pada ibu bekerja dapat mempengaruhi keberhasilan pemberian ASI di tempat bekerja. Sayangnya, 
berdasakan hasil telaah pada penelitian ini, menunjukkan bahwa dukungan formal dari tempat bekerja untuk menyusui masih relatif rendah (Brown, Poag \& Kasprzycki, 2001). Tidak terdapat riset yang menunjukkan tentang dukunGan yang diberikan pada ibu bekerja di Indonesia. Walaupun demikian, sebuah penelitan menunjukkan bahwa ibubekerja cenderung untuk memperkenalkan susu formula lebih awal dari pada ibutidak bekerja (Greta et al 2002).

Bersadarkan permasalahan yang timbul pada ibu bekerja dan menyusui maka perlunya dilakukan suatu perubahan. Tempat bekerja merupakan suatu tempat bekerja yang menuntut pekerjanya untuk menaati peraturan jam kerja yang terbilang ketat sehingga menungkinkan untuk tercipta suasana yang tidak mendukung untuk pemenuhan hak anak dengan mengkonsumsi asi saja pada usia kurang dari 6 bulan. Faktor yang dapat membantu pemberian ASI pada ibu bekerja adalah mengembangkan strategi yang tepat untuk dalam pemberian ASI sambil bekerja (Rojjanasrirat, 2004, Johnston and Esposito, 2007) dan adanya model peran yang telah berhasil dalam pemberian ASI sambil bekerja (Rojjanasrirat, 2004).

\section{METODE PELAKSANAAN}

Metode kegiatan, kegiatan ini berbentuk penyuluhan dan pelatihan tentang memerah ASI pada ibu bekerja. Kegiatan ini bersifat penunjang kegiatan Puskesmas dalam rangka meningkatkan derajat kesehatan masyarakat seoptimal mungkin pada pos KIA (kesehatan ibu dan anak), agar ibu bekerja tetap memberikan asi nya kepada anak. Persiapan meliputi perizinan, pengajuan ijin kepada lembaga pengabdian masyarakat unsri yang ditujukan kepada perusahaan. Berkoordinasi dengan Pihak manajemen untuk jadwal kegiatan posyandu atau kegiatan KIA. Khalayak sasaran dalam kegiatan pengabdian ini adalah ibu-ibu karier atau ibu-ibu yang bekerja, baik diperkebunan atau ibu bekerja dikantoran yang mempunyai anak bayi 1-6 bulan di tempat kerja. Potensi mitra kegiatan yang terlibat adalah kader dan ibu PKK dan Bidan desa, yang dalam hal ini kader sebagai pelaksana perpanjangan kegiatan program yang ada di PUSKESMAS, sehingga berpotensi mampu menggerakan ibu-ibu yang mempunyai anak untuk tetap memberikan ASI ekslusifnya selama 6 bulan tanpa pengganti, walaupun sambil bekerja atau ibu dengan status ibu karier.

\section{HASIL DAN PEMBAHASAN}

\section{A. Pelaksanaan.}

Pelaksanaan pengabdian kepada masyarakat ini di awali dengan beberapa kegiatan diantaranya: briefing yang dilakukan tiga kali, pelaksanaan dan evaluasi, dan pendampingan pada peserta pelatihan. 


\section{Briefing.}

Briefing pertama pemberitahuan kepada team, bahwa ajuan pengabdian di danai oleh lembaga pengabdian masyarakat unsri, briefing kedua, mendiskusikan rencana pelaksanaan pengabdaian, mulai dengan siapa dan akan mengerjakan apa, briefing ketiga menindak lanjuti dari briefing kedua, dimana pada briefing ke dua sudah di lakukan pengorganisasian pekerjaan, dan pada briefing ketiga ini juga lebih ke arah evaluasi yang sudah di siapakan pada briefing kedua, termasuk penyamaan persepsi kepada seluruh anggota team pelaksana pengabdaian.

\section{Pelaksanaan dan evaluasi.}

Pelaksanaan pengabdaian kepada masyarakat di lakukan pada tanggal 22 Oktober 2018. Pelaksanaan pengabdaian ini di bagi menjadi beberapa tahap, yaitu: penyuluhan materi ASI Ekslusif, penyuluhan materi ASI Perah (meliputi materi dan menyaksikan video), dan selanjutnya di lakukan evaluasi menggunakan metode tanya jawab kepada peserta.

\section{B. Pembahasan}

Kegiatan penyuluhan dan pendampingan pemberian ASI ekslusif oleh ibu yang mempunyai anak usia 0-6 bulan merupakan bentuk nyata trias prevensi yang harus dilakukan oleh tenaga kesehatan terutama perawat di PUSKESMAS. Program ini di puskesmas dilakukan oleh program promosi kesehatan dan program KIA (kesehatan ibu dan anak). WHO merekomendasikan pemberian ASI secara eksklusif selama 6 bulan pertama kehidupan bayi, artinya bayi hanya menerima asi sebagai sumber nutrisi dan cairan bayi sampai bayi berusia 6 bulan (Quigley, Kelly \& Sacker, 2007; Sisk, et al, 2007; Kramer et al, 2008; Riordan \& Auerbach, 1993; WHO, 2001). Beberapa hal yang menghambat pemberian ASI eksklusif diantaranya adalah rendahnya pengetahuan ibu dan keluarga lainnya mengenai manfaat ASI dan cara menyusui yang benar, kurangnya pelayanan konseling laktasi dan dukungan dari petugas kesehatan, faktor sosial budaya, gencarnya pemasaran susu formula, dan faktor ibu yang bekerja (Dinkes,2008).

Hal yang menjadi perhatian bagi ibu bekerja dalam pemberian ASI adalah bagaimana mempertahankan produksi ASI selama jam kerja. Pengeluaran ASI yang teratur dan adanya fasilitas penyimpanan ASI merupakan salah satu cara untuk mengatasi masalah tersebut karena pengeluaran ASI secara teratur akan merangsang produksi ASI lebih banyak. (Bocar, 1997). Thompson (dikutip dalam Wy att 2002) mengidentifikasi 5 fasilitas yang dapat disediakan oleh tampat kerja untuk tetap memberikan ASI yaitu: pompa ASI, ruangan untuk memerah ASI atau ruangan untuk menyusui, waktu istirahat untuk memerah ASi atau untuk menyusui, adanya lemari pendingin untuk tempat menyimpanASI dan adanya dukungan dari tempat bekerja.

Terdapat 2 jenis cara untuk memerah ASI yaitu memerah ASI dengan tangan dan menggunakan pompa ASI. Memerah ASI dengan tangan sangat disarankan karena paling mirip dengan perilaku bayi pada saat menyusu pada ibunya. Memerah ASI dengan tangan akan memberikan stimulasi 
taktil pada areola yang akan memberikan tekanan pada kantong ASI. Ibu yang memerah ASI menggunakan tangan akan terhindar dari masalah mekanis yang ditemui pada pada ibu yang memompa ASI seperti pompa yang rusak, baterai atau listrik yang tidak bekerja. Secara umum terdapat 2 jenis pompa ASI yaitu pompa ASI manual dan pompa listrik. Penggunaan pompa listrik disarankan pada ibu yang bekerja lebih dari 8 jam dan memiliki masalah dengan waktu memompa (Bocar, 1997).
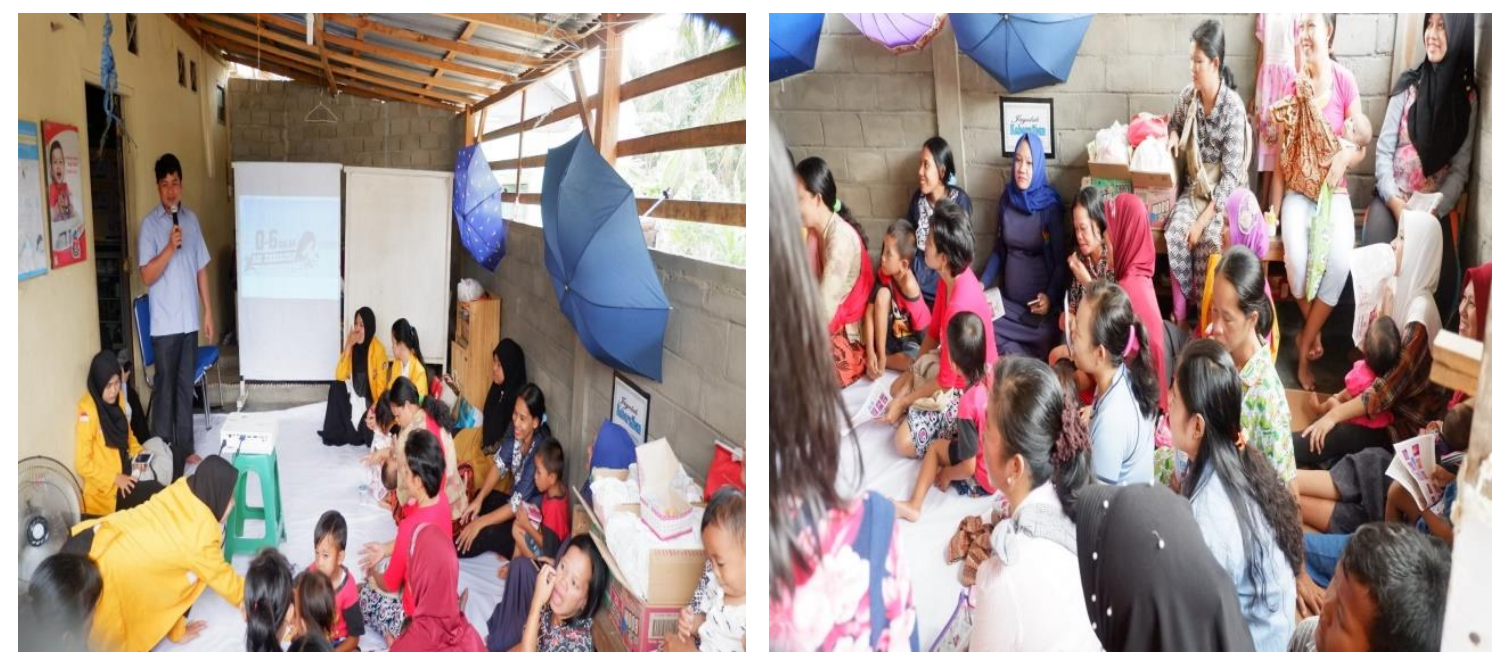

Slusser et al (2004) telah meneliti tentang praktek manajeman laktasi pada ibu bekerja. Penelitiannya dilakukan pada suatu perusahaan yang memberikan fasilitas memiliki fasilitas laktasi termasuk adanya pompa ASI dua corong di ruang laktasi pada saat jam kerja. Penelitian ini menemukan bahwa ibuyang berkerja selama 8 (delapan) jam membutuhkan waktu selama 2-3 kali selama 30 menit untuk memompa ASI. Penelitian ini menyarankan kepada ibu bekerja untuk memerah atau memompa ASI setiap 3 jam termasuk pada waktu makan siang. Sehingga ibu bekerja yang menyusui harus mengatur waktunya sebaik mungkin sehingga memiliki waktu untuk istirahat dan makan siang yang akan mempengaruhi produksi ASI (Meek, 2001). ASI yang telah di pompa dapat disimpan dalam wadah tertutup rapat dan dapat disimpan pada suhu ruangan selama maksimal 8 jam. Jika disimpan di lemari pendinginASI dapat dismpan selama 8 jam sedangkan jika di simpan di dalam freezer ASI dapat disimpan selama 12 bulan (Bocar 1997).

Beberapa hal yang dapat menfasilitasi pemberian ASI pada ibu bekerja yaitu dukungan lingkungan kantor dukungan dari atasan, teman kerja, jadual kerja yang fleksibel, waktu istirahat, sikap rekan kerja yang positif terhadap pemberian ASI, sikap ibu bekerja (komitmen, determinasi, dedikasi dan kesadaran tentang manfaat pemberian ASI) dan perencanaan strategis (manajemen waktu, kemampuan mempertahankan produksi ASI dan kemampuan menjaga kesehatan). Sedangkan beberapa hal yang dapat menghambat pemberian ASI adalah stress psikologis yang disebabkan oleh waktu bekerja yang ketat dan ketidak nyamanan pada saat pemberian ASI. Kurangnya waktu dan 
lokasi ruangan menyusui juga diakui sebagai salah satu hambatan dalam pemberain ASI selama jam kerja.

Memerah ASI merupakan salah satu solusi untuk tetap memberikan ASI di tempat kerja. Salah satu kendala dalam memerah ASI adalah keterbatasan waktu untuk memerah ASI dan tidak tersedianya tempat untuk menyimpan ASI perahan di kantor. Dukungan lain yang dibutuhkan oleh pekerja ibu untuk mempertahankan pemberian ASI adalah informasi tentang manajemen pemberian ASI pada saat kembali bekerja, adanya fasilitas untuk memerah dan menyimpan ASI, waktu kerja yang fleksiabel dan adanya istirahat khusus untuk memerah ASI (Kosmala-Anderson dan Wallace, 2006). Faktor yang dapat membantu pemberian ASI pada ibu bekerja adalah mengembangkan strategi yang tepat untuk dalam pemberian ASI sambil bekerja dan adanya model peran yang telah berhasil dalam pemberian ASI sambil bekerja.

\section{SIMPULAN DAN SARAN}

Rendahnya cakupan pemberian ASI merupakan ancaman bagi tumbuh kembang anak. Beberapa hal yang menghambat pemberian ASI eksklusif diantaranya adalah rendahnya pengetahuan ibu dan keluarga lainnya mengenai manfaat ASI dan cara menyusui yang benar, kurangnya pelayanan konseling laktasi dan dukungan dari petugas kesehatan, faktor sosial budaya, gencarnya pemasaran susu formula, dan faktor ibu yang bekerja. Sedangkan beberapa hal yang dapat menghambat pemberian ASI adalah stress psikologis yang disebabkan oleh waktu bekerja yang ketat dan ketidak nyamanan pada saat pemberian ASI. Kurangnya waktu dan lokasi ruangan menyusui juga diakui sebagai salah satu hambatan dalam pemberain ASI selama jam kerja.

Kegiatan penyuluhan dan pendampingan pemberian ASI ekslusif oleh ibu yang mempunyai anak usia 0-6 bulan merupakan bentuk nyata trias prevensi yang harus dilakukan oleh tenaga kesehatan terutama perawat di PUSKESMAS. Program ini di puskesmas dilakukan oleh program promosi kesehatan dan program KIA (kesehatan ibu dan anak). Memerah ASI merupakan salah satu solusi untuk tetap memberikan ASI di tempat kerja. 5 fasilitas yang dapat disediakan oleh tampat kerja untuk tetap memberikan ASI yaitu: pompa ASI, ruangan untuk memerah ASI atau ruangan untuk menyusui, waktu istirahat untuk memerah ASI atau untuk menyusui, adanya lemari pendingin untuk tempat menyimpanASI dan adanya dukungan dari tempat bekerja.

Saran dari pengabdian ini ditujukan kepada para ibu mempunyai anak bayi umur 0-6 bulan yang bekerja agar berkomitmen ketika mempunyai anak akan memberikan ASI ekslusif kepada anaknya, dan bagi ibu yang sedang mempunyai anak bayi usia 0-6 bulan agar tetap memberikan asi ekslusif walaupun sambil bekerja yaitu dengan memberikan asi perah. Sedangkan bagi institusi agar 
memberikan kesempatan kepada ibu yang mempunyai anak usia 0-6 bulan, tetap memberikan asinya dengan melonggarkan waktu untuk manajemen asi perah.

\section{DAFTAR PUSTAKA}

Biagioli, F. (2003). Returning to work while breastfeeding'. American Family Physician, 68(11), 2199-2206

Bridges, C.B., Frank, D.I. \& Curtis, J. (1997). Employers attitude towards breastfeeding in the workplace'. Journal of Human Lactation, 13(3), 215-219

Earlan, J, Ibrahim, SO \& Harpin, VA (1997), 'Maternal employment : does it influence fe eding practice during infancy?', Journal of Human Nutrition and Dietetics, 10, 305-311

Greta,A, Stevenhuysen, G, Gross, U \&Sastromidjojo, S (2002), 'Complementary feeding patterns in Pondok Labu, South Jakarta, Indonesia', Breastfeeding review, 10 (1), 19-24

Kimbro, RT (2006), 'On-the-job moms: work and breastfeeding initiation and duration for a sample of low-income women', Maternal and Child Health Journal, 10 (1), 19-26

Rojjanasrirat, W (2004),' Working women's breastfeeding experinces', $M C N, 29$ (4), 222- 227 Ry an, AS, Zhou, W \& Arensberg, MB (2006), 'The effect of employment status on breastfeeding in the United States', Women's health issues, 16, 243-251

World Health Organization (2001), Global strategy fo $r$ infant and young child feeding: The optimal duration of exclusive breastfeeding. 54th World HealthAssembly ProvisionalAgenda Item 13.1, A54/INF/DOC/4.

Quigley, MA, Kelly, YJ, Sacker, A (2007), 'Breastfeeding and hospitaliztion for diarrheal repiratory infection in the United Kingdom millenium cohort study', Pediatrics, 19 (4), e837-e842

Kramer, AF, Mironova, E, Vanilovich, I, Platt, RW.Matush, L, Igumnov, S., Fombonne, E.,Bogdanovich, N., Ducruet, T, Collet, J,Chalmers, B, Hodnett, E, Davidovsky,S,Skugarevsky, Trofimovich, O., Kozlova, L.,Shapiro, S., (2008); Promotion of BreastfeedingIntervention Trial (PROBIT) Study Group Breastfeeding and Child CognitiveDevelopment: New Evidence From a LargeRandomized Trial. Archives of GeneralPs ychiatry. 65(5), 578-584

Riordan, J \&Auerbach, K (1993), 'Breastfeeding andhuman lactation'Jones \& Bartlett, London

Palda, V.A. (2004). Interventions to promote breast-feeding: applying the evidence in clinical practice diakses di http://www.ncbi.nlm.nih.gov/pmc/articles

Ray. (2013). PNS lebih berpeluang memberikan ASI eksklusif diakses di www.kompas.com

WHO. (2002). Global Strategy for Infant and Young Child Feeding diakses di http://www.who.int/nutrition/topics/global_strategy/en/ 
JAMALI - Volume. 02, Issue. 02, September 2020

Bar-Yam NB, Darby L (1997) Fathers and breastfeeding: a review ofthe literature. J Hum Lact, 13:45-50. 